Article

\title{
Small Wind Technology Diffusion in Suburban Areas of Sicily
}

\section{Simona Culotta ${ }^{1, *}$, Vincenzo Franzitta ${ }^{2}$, Daniele Milone ${ }^{2, *}$ and Gino Moncada Lo Giudice ${ }^{3}$}

1 Scuola Politecnica-Università di Palermo, Viale delle Scienze ed. 9, Palermo 90128, Italy

2 DEIM - Dipartimento Di Energia, Ingegneria Dell'informazione e Modelli Matematici, Università di Palermo, Palermo 90128, Italy; E-Mail: franzitta@dream.unipa.it

3 Universita La Sapienza Roma, Piazzale Aldo Moro 5, 00185 Roma, Italy;

E-Mail: gino.moncada31@gmail.com

* Authors to whom correspondence should be addressed;

E-Mails: simonaculotta@dream.unipa.it (S.C.); daniele.milone@unipa.it (D.M.);

Tel.: +39-338-158-2645 (S.C.); +39-091-2386-1944 (D.M.).

Academic Editor: Marc A. Rosen

Received: 19 May 2015 / Accepted: 9 September 2015 / Published: 16 September 2015

\begin{abstract}
Among renewable energy resources, wind energy became more attractive in the last decade. Wind farm installations dramatically increased in areas where climatic conditions, topography, and environment have allowed their development. The installation of wind turbines, usually carried out in remote areas, recently began to cover areas identified by a complex terrain such as urban and suburban zones. Although these new plant choices are characterized by lower productivity, there is increasing interest in wind energy production in both urban and suburban areas. In this work the authors have carried out an energy analysis developed from a sample of small wind turbines available on the market. This study shows how variable the energy production of a small wind turbine can be according to many design and context parameters: wind profiles, installation height, land use, and characteristics of the turbine.
\end{abstract}

Keywords: energy; renewable energy; wind energy; wind turbines

\section{Introduction}

In the last years, due to the boom of renewable energy, the attention researchers have paid to wind power has had a rapid increase. The knowledge of the wind system in a site is crucial for exploiting 
wind energy. Many studies, reported in the literature, have focused on the estimation of the potential of wind power in different parts of the world and concern the calculation of wind speed frequency distribution [1-5]. In the literature are also present others studies focused on extrapolation of the vertical profile of wind speeds. However, these articles have focused on large-scale turbines and few are the examples on the potential of wind energy production in urban and suburban areas. As is well known, wind energy can be used not only in large systems but also in small installations [6,7]. Thanks to advances in this technology, and to the recent introduction of specific economic incentives, these systems of power generation are showing a real opportunity to grow. However, the efficacy of an energy policy based on the use of these systems is not possible without a preliminary analysis of the sites aimed at addressing the use of financial resources instead of sites characterized by good energetic potential [8-10]. The choice and location of a small turbine in a place where air velocity may be strongly influenced by the presence of natural or artificial obstacles is not an easy task. Reliable evaluation of the energy production requires good information about wind and site characteristics. The aim of this study is to present an energy analysis developed from a set of small-scale turbines available on the market be inserted in the suburban areas of Sicily.

\section{Italian Regulatory Framework}

The first norms suitable for regulatory authorization procedures for the encouragement of systems to produce electricity from small wind turbines (power systems less than or equal to $200 \mathrm{~kW}$ ), were introduced in Italy with the Financial Law 2008 and the Ministerial Decree, dated 18 December 2008, on incentives of electricity generation from renewable sources. By the establishment of regional energy plans and documents of territorial planning, the Financial Law 2008 refers to the regional wind power regulating the opportunity to decide the sites in which it is possible to build wind farms and regulate the size of the system, requiring a procedure for environmental impact assessments. The Italian legislation provides that the systems in size up to $60 \mathrm{~kW}$, installed in areas in which there is no Special Protection Area or Sites of Community Importance is authorized by a simple declaration of the opening activity (DIA) by the municipality that it located near the installation site. For systems over $60 \mathrm{~kW}$, or if the installation is in proximity of protected areas, the regions and provinces established the need to perform an environmental impact assessment process in order to obtain the necessary qualifying title: DIA/Unique Authorization. For lines from $6 \mathrm{MW}$ partner for the practice of connecting is the local power distributor who, after doing an inspection, must agree to connect according to the electrical standards of the wind turbine. The local distribution company must also provide the details of expenditures to be incurred during the authorization process and for any works to be carried out in order to adjust the network connection. The Finance Law indicates the incentive recognized for systems between $1 \mathrm{~kW}$ and $200 \mathrm{~kW}$, in the form of the Energy Account, is $300 € / \mathrm{MWh}$ for energy produced and fed into the network (in low or medium voltage). This incentive, comprehensive of quota sale, replaces the green certificate (GC), which was not always advantageous. The GC should be treated as a title on the appropriate market and it is often realized at a figure less than the nominal value. The opportunities offered by the new Italian regulatory framework allow one to address greater attention to a potential market of larger size compared to what was done until today and promised a significant spread of wind turbines to small and medium 
size until now neglected. It is assumed that this will lead to reduced costs of industrial development, distribution and greater competitiveness of the technology.

\section{Small Wind Turbines Available on the Market}

Wind turbines convert the kinetic energy in the wind into mechanical power [11]. It consists of a certain number of blades (usually three) fixed to a crankshaft. There are two kinds of wind turbines, the vertical axis wind turbine (VAWT) and the horizontal axis wind turbine (HAWT). The small horizontal axis turbines have benefited from the advancements made by machines of larger size. Generally, the smaller turbines are fixed blades and regulated for tilt or yaw, while the slightly larger sizes are often equipped with control systems for pitch control [12]. The VAWT, helped by a low environmental impact, are better adapted to be installed near residential and urban areas because they have lower start-up speed and low noise levels. These are also appropriate to be installed in areas with strong winds; the VAWT are indifferent to wind direction.

In this paper will be analyzed a set of wind turbines (horizontal and vertical axis) subdivided into six size classes $(0.5-1.8 \mathrm{~kW}$ class, 2-3.5 kW class, 5-6 kW class, 10-12.5 kW class, 15-17.5 kW class, and 20-25 kW class). The models considered are shown in Table 1 and data sheets are available on the producers' websites. The total number of analyzed products (wind turbines) is 14 .

As an example, Table 2 summarizes the technical data for the Soma 1000 turbine shown in Figure 1 and has a power curve represented in Figure 2.

Table 1. Set of wind turbines subdivided into power class.

\begin{tabular}{ccc}
\hline Power Classes & Wind Turbine Model & Producers \\
\hline \multirow{2}{*}{ Class 0.5-1.8 kW } & Soma 1000-1 kW (HAWT) & Sunrise Solar \\
& Windspire 1.2 G-1.2 kW (VAWT) & Mariah Power \\
\hline \multirow{2}{*}{ Class 2-3.5 kW } & Inclin 3000-3 kW (HAWT) & J. Bornay \\
& Windfox-3 kW (HAWT) & Italkero s.r.l \\
& WindRotor WRE.030-3 kW (VAWT) & Ropatek \\
& Cleanfield-3.5 kW (VAWT) & Cleanfield Energy \\
\hline \multirow{2}{*}{ Class 5-6 kW } & EasyWind 6 AC-6 kW (HAWT) & Conergy \\
Maxy Vertical Wre 0.62-6 kW (VAWT) & Ropatec \\
\hline \multirow{2}{*}{ Class 10-12.5 kW } & BWC Excel-S-10 kW (HAWT) & Bergey Windpower \\
\hline \multirow{2}{*}{ Class 15-17.5 kW } & Windpower Gyro-10 kW (VAWT) & Four Seasons Windpower \\
\hline \multirow{2}{*}{ Class 20-25 kW } & WT 15000-15 kW (HAWT) & Proven Energy Ltd \\
& Baywinds 24-15-15 kW (HAWT) & Baywinds \\
\hline
\end{tabular}


Table 2. Technical data for turbine Soma 1000.

\begin{tabular}{ccc}
\hline Wind Turbine & \multicolumn{1}{c}{ Technical Data } \\
\hline & Nominal Power & $1 \mathrm{Kw}$ \\
& Numbers. Blades and material, & 2 , fiberglass \\
& Rotor diameter & $2.7 \mathrm{~m}$ \\
& Cut-in wind speed & $3.5 \mathrm{~m} / \mathrm{s}$ \\
Soma 1000-1 kW (HAWT) & Cut-off wind speed & $50 \mathrm{~m} / \mathrm{s}$ \\
& Rated wind speed & $10 \mathrm{~m} / \mathrm{s}$ \\
& Security wind speed & $50 \mathrm{~m} / \mathrm{s}$ \\
& Weight nacelle & $50 \mathrm{Kg}$ \\
& Weight tower & $45 \mathrm{Kg}$ \\
& Price per kW & $1.980 € / \mathrm{kW}$ \\
\hline
\end{tabular}

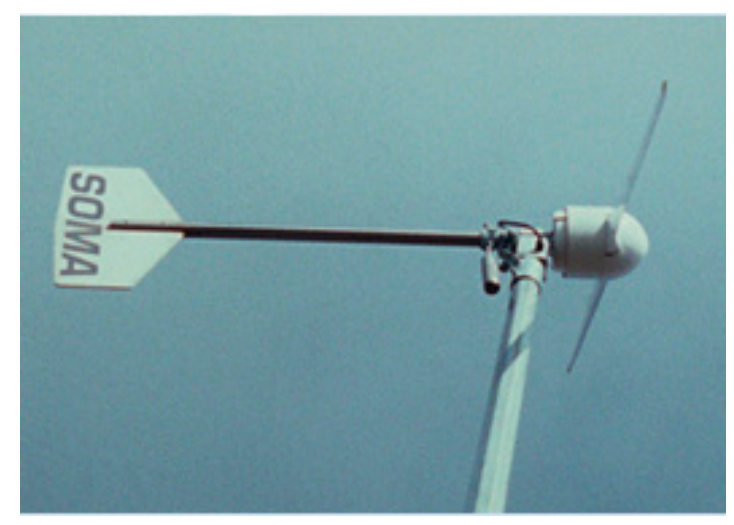

Figure 1. HAWT Soma 1000.

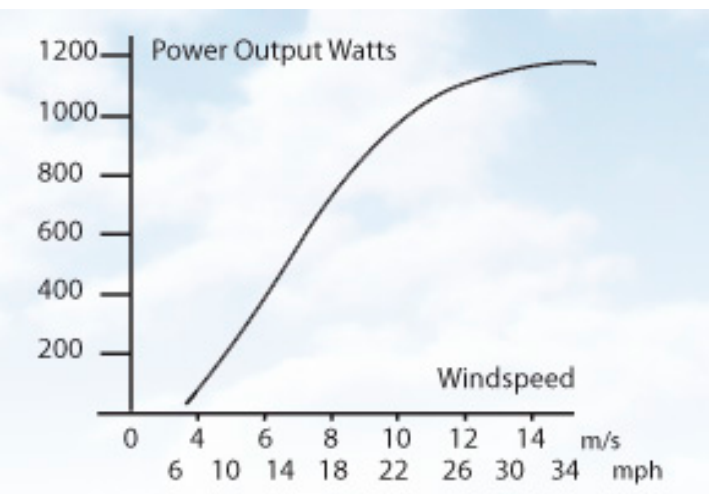

Figure 2. Power curve of Soma 1000.

\section{Techno-Economic Analysis}

\subsection{Siting}

The study of the geographical distribution of the wind is often carried out through the building of wind maps. With these maps, however, you lose the ability to take into account the local phenomena related, for example, the orography of the area. Consequently, the knowledge of the territory, combined with analysis of detected wind data, are essential for the correct choice of site, for choice of turbine to be installed, for the electricity production and, therefore, for the validity of project. The statistical 
distribution of wind speeds was considered in two different sites of Sicily (Enna and Gela identified by red marker in Figure 3) for two different land types: "rural area" and "suburban area".

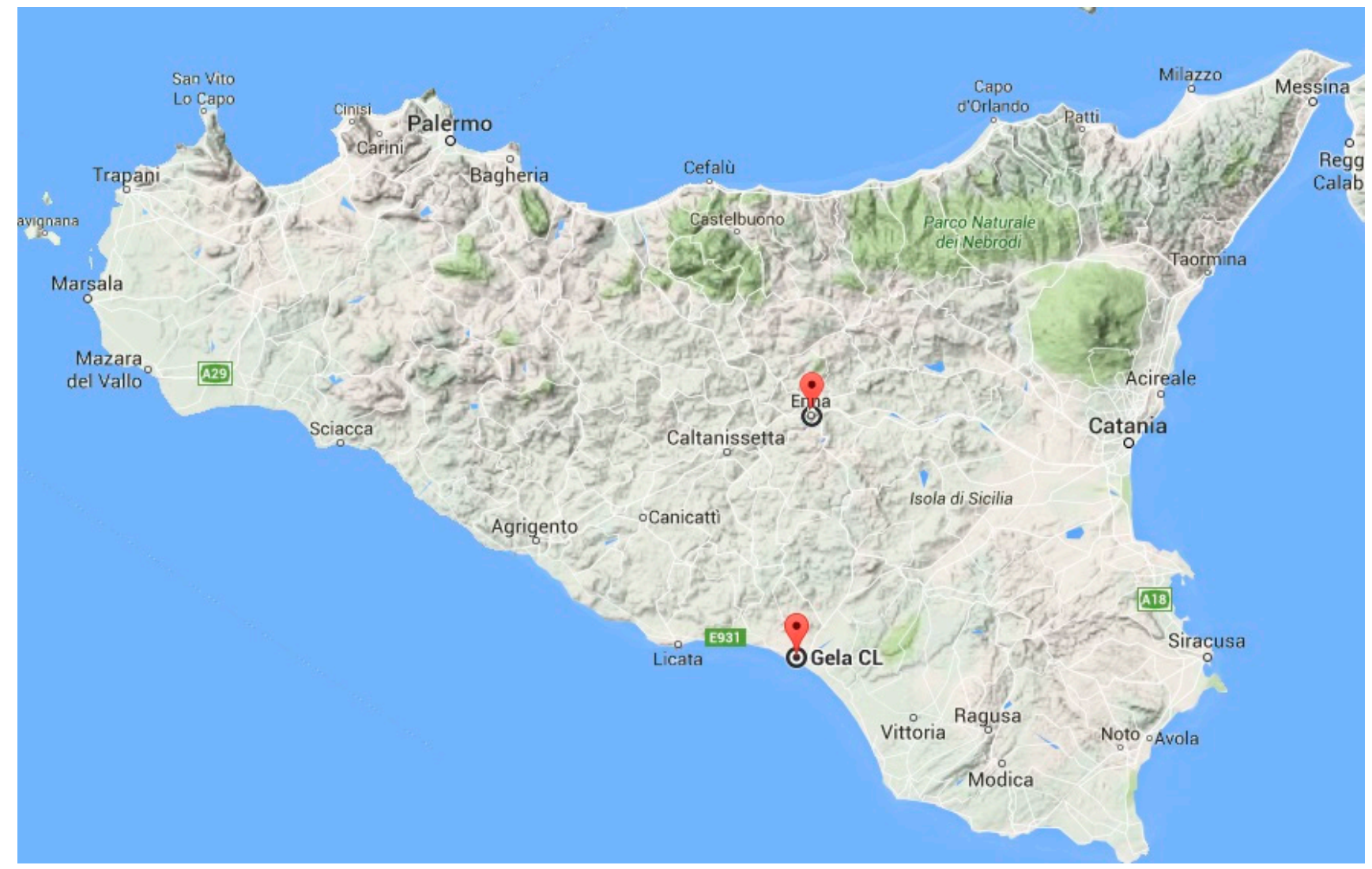

Figure 3. Anemometric stations.

\subsection{Energy Analysis}

In the evaluation of energy capability of a system are two key aspects: the characteristics of wind at the sites under consideration and the features of the turbine to be installed [13]. In order to calculate the power from a wind turbine over a range of wind speeds a generalized expression is needed for the probability density distribution. An expression which gives a good fit to wind data is known as the Weibull distribution [14]:

$$
t(v)=\frac{k}{c}\left(\frac{v}{c}\right)^{k-1} \exp \left[-\left(\frac{v}{c}\right)^{k}\right]
$$

where $v$ is the wind speed $(\mathrm{m} / \mathrm{s}), c$ is the scale factor $(\mathrm{m} / \mathrm{s})$, and $\mathrm{k}$ is the shape factor (dimensionless).

The scale parameter is related in a univocal way to the average speed, is directly proportional to it, and from which does not differ much in numerical terms. The shape factor is a dimensionless term that characterizes the amplitude of the wind speed dispersion around the mean. This parameter, such as that of scale, is typical of a site under investigation and should be obtained by a measurement campaign. When this is not possible, one should take a guide value based on the climatic conditions of the area under study or similarity to other sites in the same climatic area. The shape factor is, therefore, an irregularity index of the wind regime. 
Mountain areas and urban areas characterized by very irregular winds have values of $\mathrm{k}$ between 1 and 1.5 , ocean areas with very regular winds have a value between 2.5 and 4, and the coastal areas in temperate areas have a value of $\mathrm{k}$ around 2.

The Weibull distribution expressed by Equation (1) falls into default when the wind speed is null. In order to take this into account the calm wind frequency (" $s$ " in percentage) must be considered. The parameters used in this study are summarized in Table 3.

Table 3. Parameters for Enna e Gela.

\begin{tabular}{cccc}
\hline Stations & $\mathbf{c}(\mathbf{m} / \mathbf{s})$ & $\mathbf{k}$ & $\boldsymbol{s} \%$ \\
\hline Enna & 6.23 & 1.83 & 11.39 \\
Gela & 4.65 & 1.46 & 7.22 \\
\hline
\end{tabular}

Due to the fact that each turbine can be installed on towers at different lengths, it is necessary to calculate the trend of the wind speed $v$ according to quota $h$ (vertical velocity profile). This trend is usually expressed by the following relationship:

$$
v=v_{0}\left(\frac{h}{h_{0}}\right)^{\alpha}
$$

where $v$ is the wind speed at the height to be extrapolated, $v_{0}$ is the wind speed recorded by meteorological station from the ground level $h_{0}(10 \mathrm{~m})$, and the power law exponent $\alpha$ is the wind shear exponent. This parameter is generally between 0.1 and 0.4 and depends on the surface roughness, atmospheric stability, and height range

Figures 4 and 5 show the speed profiles for the two locations under investigation regarding both types of soil analyzed. In red is the speed measured in the region of $10 \mathrm{~m}$ above ground level.

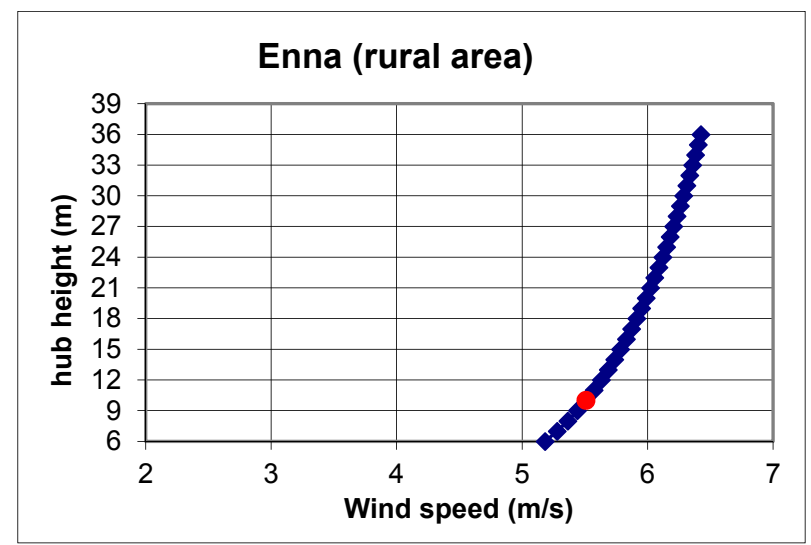

(a)

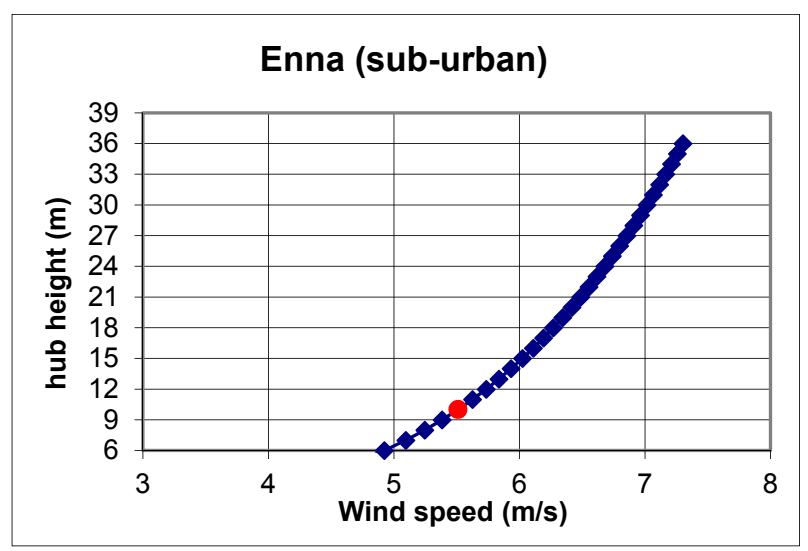

(b)

Figure 4. (a) Wind velocity profile for Enna rural area; (b) Wind velocity profile for Enna sub urban area. 


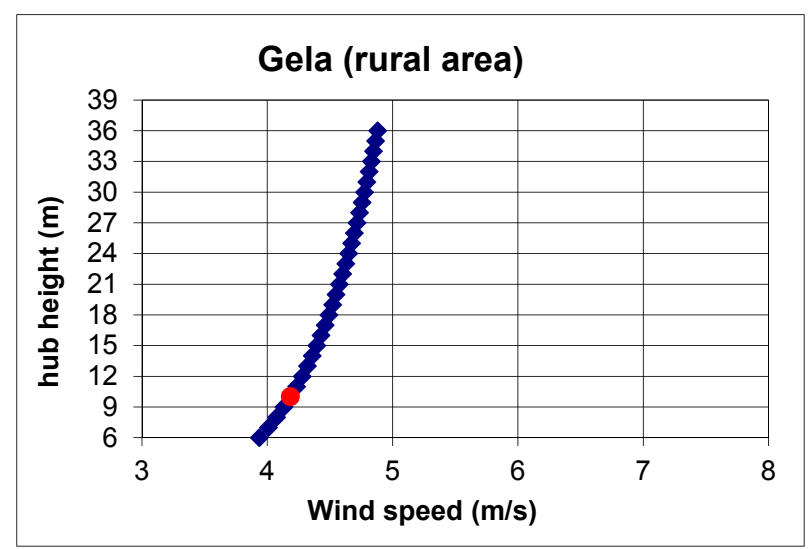

(a)

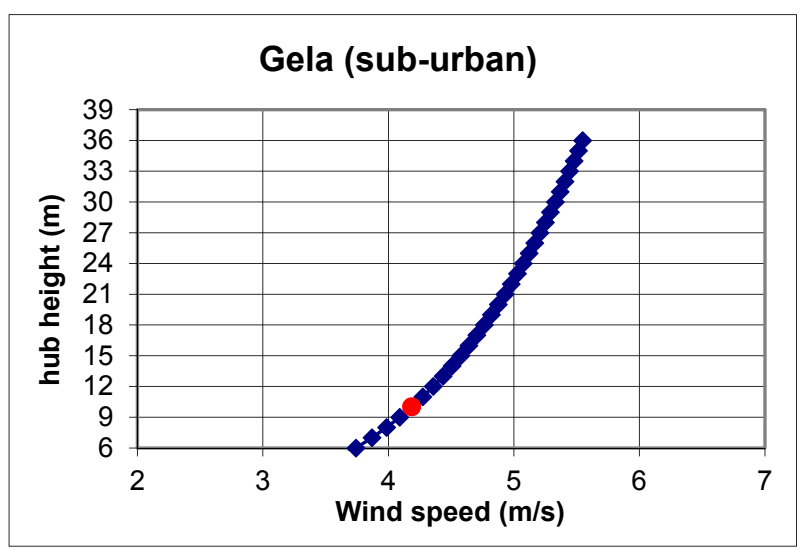

(b)

Figure 5. (a) Wind velocity profile for Gela rural area; (b) Wind velocity profile for Gela sub urban area.

From knowledge of the parameters of the Weibull distribution and of the profile of wind speed at different heights for the two types of terrain the curves $t(v i)$, where the index $i$ is relative to the height for which the curve was plotted (Figures 6-9). The heights considered (10, 15, 20, 25, and $30 \mathrm{~m}$ ) are those set out by producers, themselves, $s$ to the towers of the respective turbines. Figures 6 and 7 (relating the station of Enna) show a flattening with respect to the curves in Figures 8 and 9 (relating the station of Gela). This flattening is more important, the higher the shape parameter $k$. This is due to an increase in average wind speed according to the quota [15].

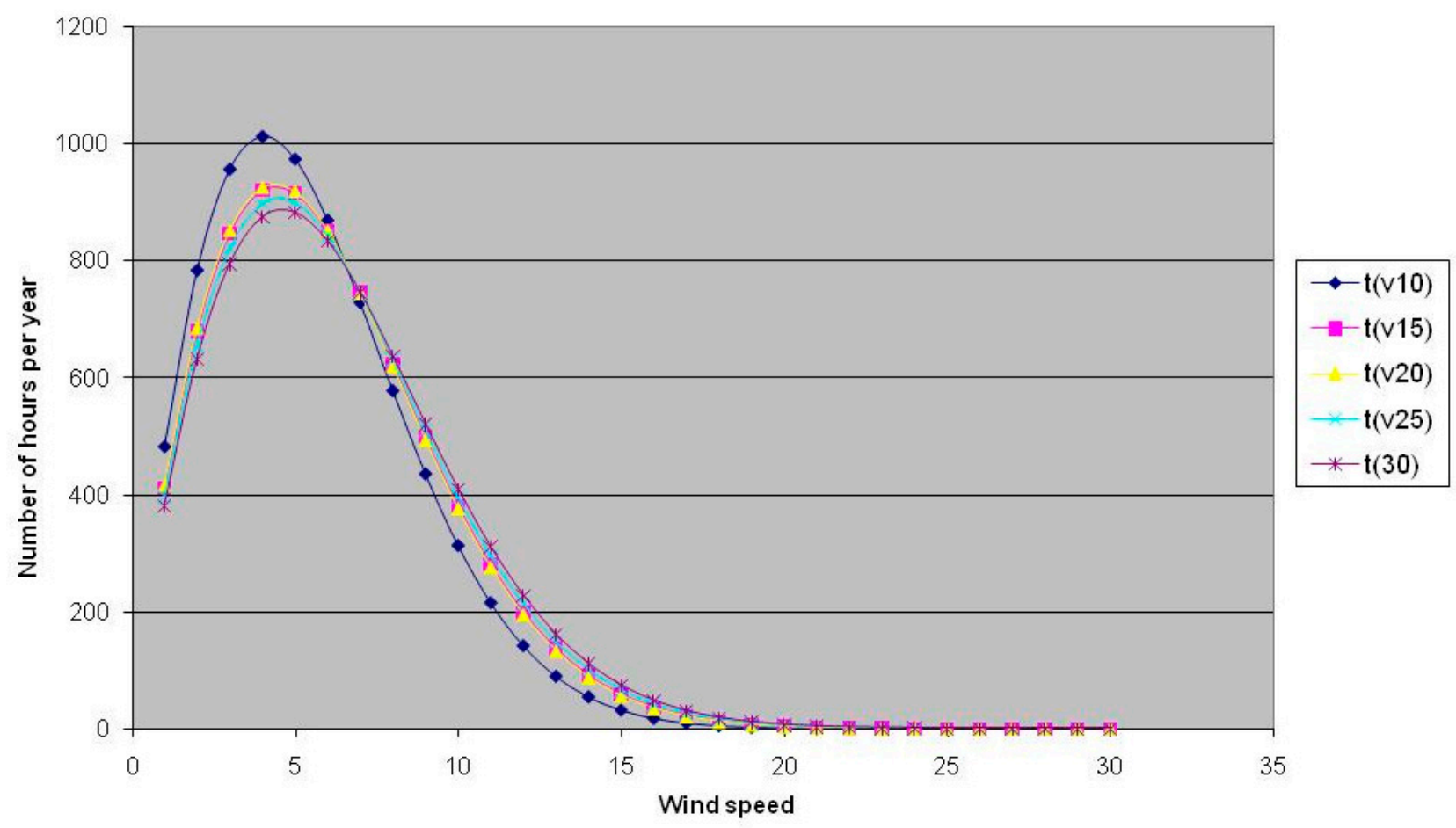

Figure 6. Wind speed distribution for different heights (Enna rural area). 


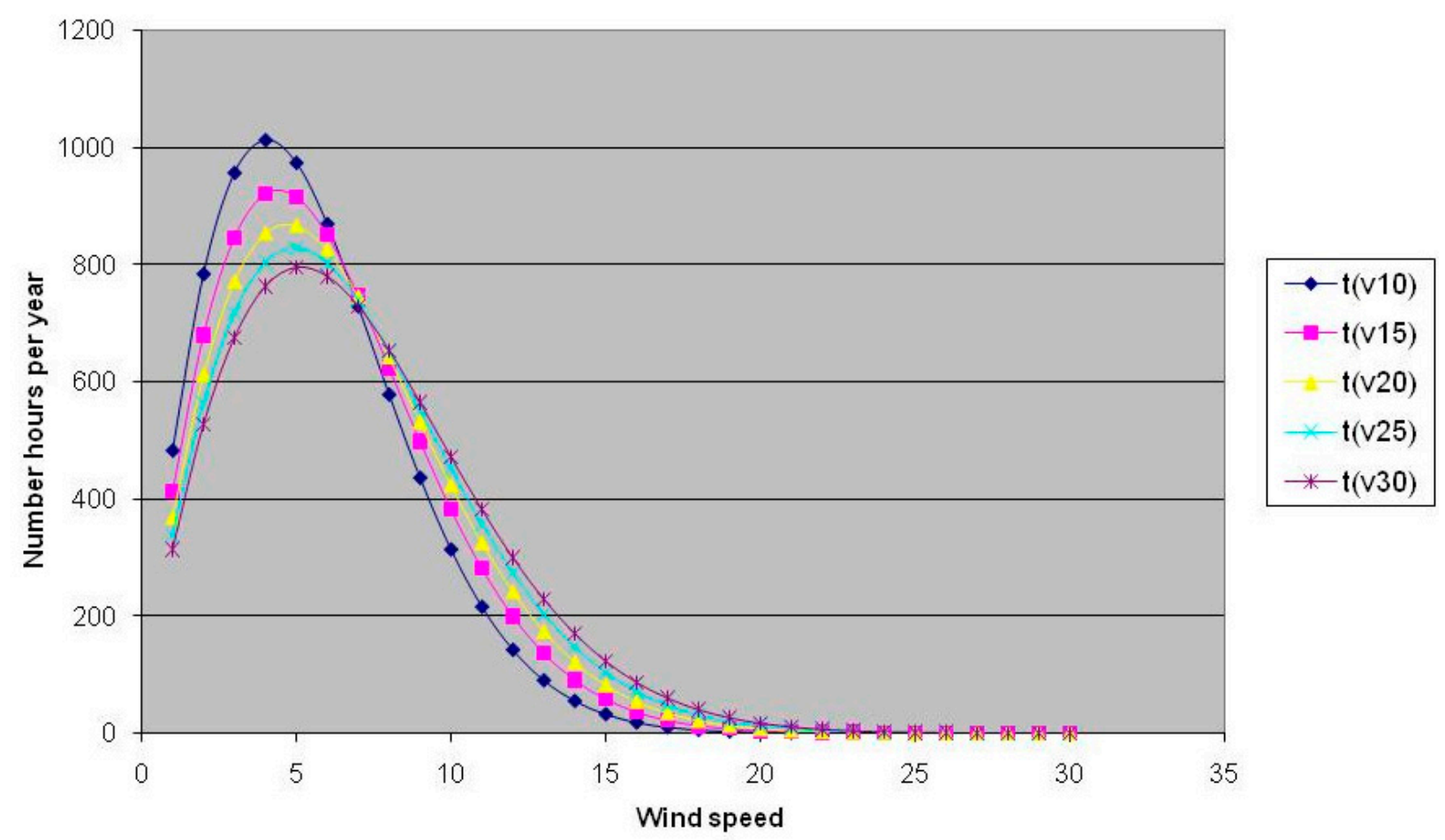

Figure 7. Wind speed distribution for different heights (Enna sub urban area).

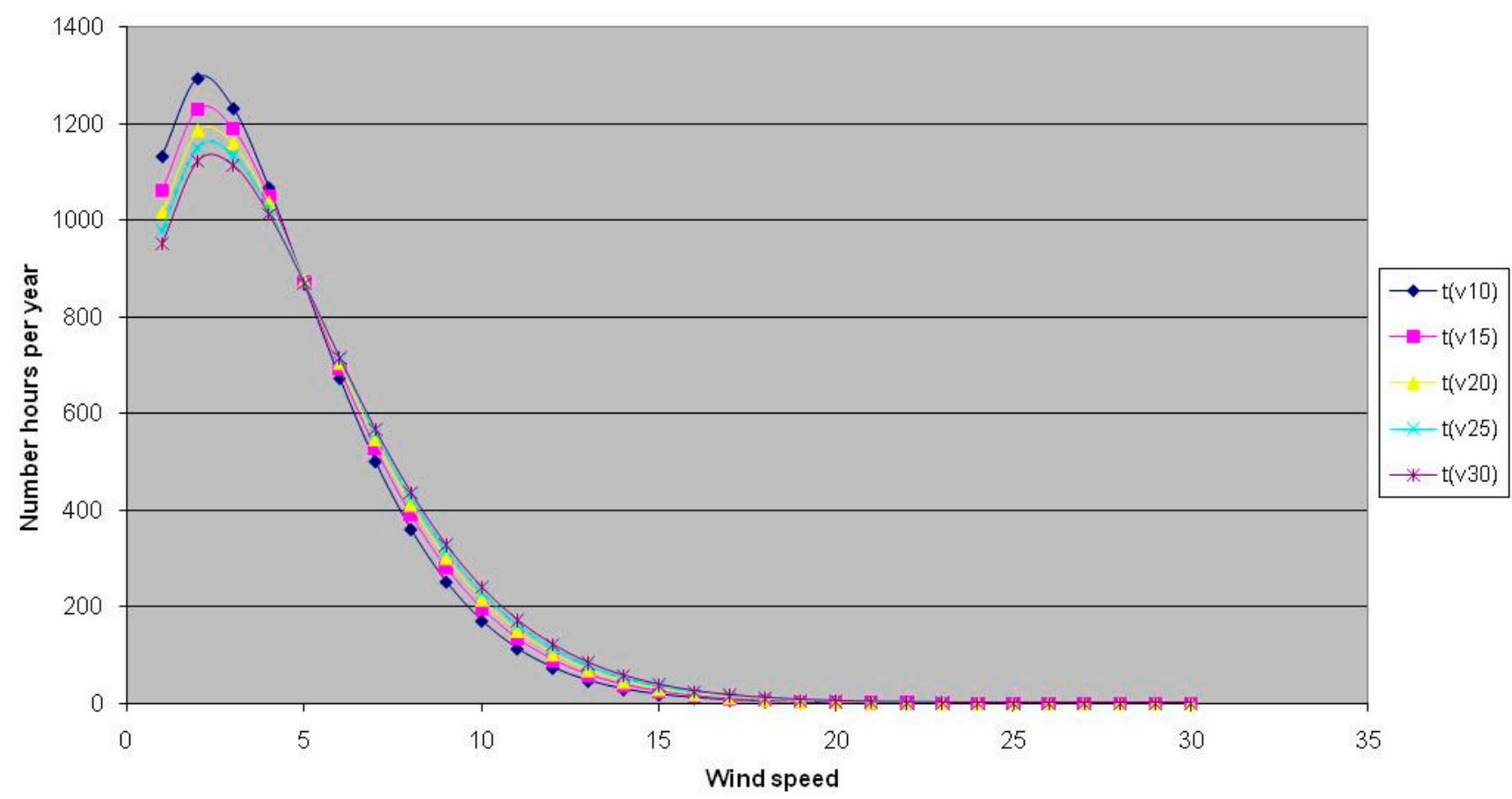

Figure 8. Wind speed distribution for different heights (Gela rural area). 


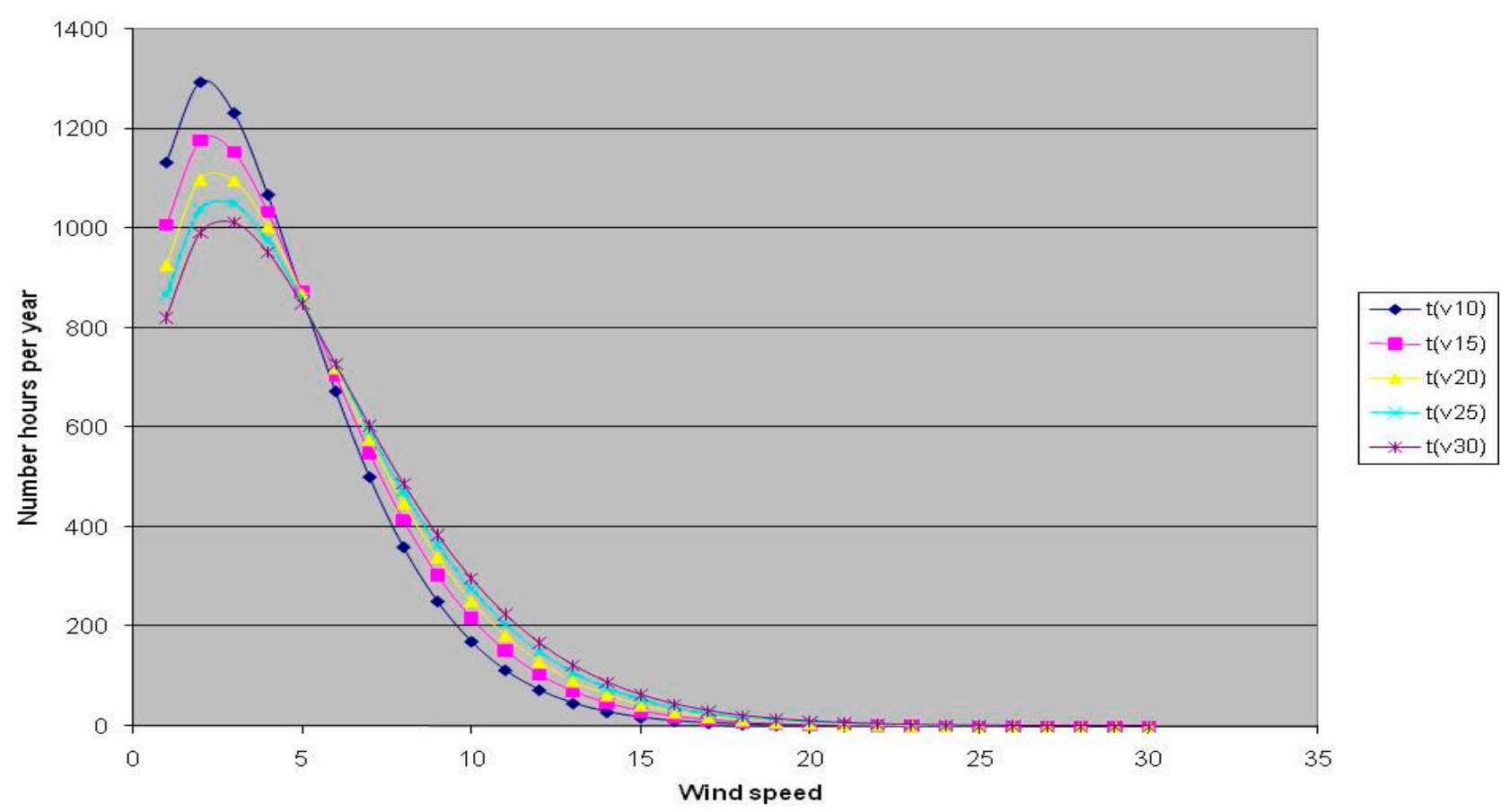

Figure 9. Wind speed distribution for different heights (Gela suburban area).

Constructed for each site, the curves' $t(v)$ calculated the electrical production of each turbine, considering for each of them the different heights of the tower, as suggested by the producers.

If the measured site wind speed data is available, then the energy yield of a wind turbine can be estimated by combining the binned wind speed distribution with the power curve:

$$
\text { Energy }=\sum_{i=1}^{i=n} H\left(U_{i}\right) P\left(U_{i}\right)
$$

where $H\left(U_{i}\right)$ is the number of hours in wind speed bin $U_{i}, P\left(U_{i}\right)$ is the power output at that wind speed and there are $n$ wind speed bins.

Tables 4 and 5 show the values of energy production of small systems, subdivided by power rating.

Table 4. Energy production kWh (Enna).

\begin{tabular}{cccccccccc}
\hline & \multicolumn{3}{c}{ Enna Sub-Urban Area } & \multicolumn{5}{c}{ Enna Rural Area } \\
\hline Class 0.5-1.8 kW & \multicolumn{3}{c}{ height (m) } & \multicolumn{5}{c}{ height (m) } \\
\hline Turbine & 10 & 15 & 20 & 25 & 10 & 15 & 20 & 25 \\
Soma 1000-1 kW (HAWT) & 2550 & 2957 & 3256 & 3490 & 2550 & 2770 & 2929 & 3055 \\
Windspire 1.2 G-1.2 kW (VAWT) & 1159 & 1459 & 1693 & 1884 & 1159 & 1318 & 1438 & 1534 \\
\hline Class 2-3.5 kW & \multicolumn{4}{c}{ height (m) } & \multicolumn{5}{c}{ height (m) } \\
\hline Turbine & 10 & 15 & 20 & 25 & 10 & 15 & 20 & 25 \\
Inclin 3000-3 kW (HAWT) & 7259 & 8260 & 8999 & 9584 & 7259 & 7798 & 8191 & 8500 \\
Windfox-3 kW (HAWT) & 8540 & 9715 & 10577 & 11259 & 8540 & 9174 & 9634 & 9995 \\
WindRotor WRE.030-3 kW & 2569 & 3186 & 3683 & 4101 & 2569 & 2893 & 3141 & 3343 \\
(VAWT) & & & & & & & & \\
Cleanfield-3.5 kW (VAWT) & 4327 & 5309 & 6080 & 6716 & 4327 & 4846 & 5238 & 5555 \\
\hline
\end{tabular}


Table 4. Cont.

\begin{tabular}{|c|c|c|c|c|c|c|c|c|}
\hline & \multicolumn{4}{|c|}{ Enna Sub-Urban Area } & \multicolumn{4}{|c|}{ Enna Rural Area } \\
\hline Class 5-6 kW & \multicolumn{4}{|c|}{ height (m) } & \multicolumn{4}{|c|}{ height (m) } \\
\hline Turbine & 10 & 15 & 20 & 25 & 10 & 15 & 20 & 25 \\
\hline EasyWind $6 \mathrm{AC}-6 \mathrm{~kW}$ (HAWT) & 13572 & 15708 & 17247 & 18443 & 13572 & 14730 & 15562 & 16212 \\
\hline Maxy Vertical Wre $0.62-6 \mathrm{~kW}$ (VAWT) & 5406 & 6760 & 7861 & 8792 & 5406 & 6115 & 6661 & 7108 \\
\hline Class 10-12.5 kW & \multicolumn{4}{|c|}{ height (m) } & \multicolumn{4}{|c|}{ height (m) } \\
\hline Turbine & 15 & 20 & 25 & 30 & 15 & 20 & 25 & 30 \\
\hline BWC Excel-S—10 kW (HAWT) & 9179 & 10807 & 12212 & 13453 & 8243 & 9035 & 9690 & 10253 \\
\hline Windpower Gyro-10 kW (VAWT) & 16123 & 18719 & 20868 & 22702 & 14575 & 15888 & 16951 & 17849 \\
\hline Class 15-17.5 kW & \multicolumn{4}{|c|}{ height (m) } & \multicolumn{4}{|c|}{ height (m) } \\
\hline Turbine & 15 & 20 & 25 & 30 & 15 & 20 & 25 & 30 \\
\hline WT $15000-15$ kW (HAWT) & 35745 & 39490 & 42418 & 44805 & 33387 & 35392 & 36966 & 38262 \\
\hline Baywinds $24-15-15 \mathrm{~kW}$ (HAWT) & 22633 & 26003 & 28773 & 31121 & 20607 & 22325 & 23711 & 24877 \\
\hline Class 20-25 kW & \multicolumn{4}{|c|}{ height (m) } & \multicolumn{4}{|c|}{ height (m) } \\
\hline Turbine & 15 & 20 & 25 & 30 & 15 & 20 & 25 & 30 \\
\hline FL $-20 \mathrm{~kW}(\mathrm{HAWT})$ & 57902 & 63288 & 67381 & 70647 & 54416 & 57385 & 59679 & 61541 \\
\hline Big Star Vertical—20 kW (VAWT) & 24074 & 27756 & 30870 & 33571 & 21920 & 23744 & 25239 & 26512 \\
\hline
\end{tabular}

Table 5. Energy production kWh (Gela).

\begin{tabular}{|c|c|c|c|c|c|c|c|c|}
\hline & \multicolumn{4}{|c|}{ Gela Sub-Urban Area } & \multicolumn{4}{|c|}{ Gela Rural Area } \\
\hline Class $0.5-1.8 \mathrm{~kW}$ & \multicolumn{4}{|c|}{ height (m) } & \multicolumn{4}{|c|}{ height (m) } \\
\hline Turbine & 10 & 15 & 20 & 25 & 10 & 15 & 20 & 25 \\
\hline Soma $1000-1 \mathrm{~kW}$ (HAWT) & 1678 & 1982 & 2213 & 2399 & 1678 & 1841 & 1961 & 2057 \\
\hline Windspire $1.2 \mathrm{G}-1.2 \mathrm{~kW}$ (VAWT) & 689 & 881 & 1037 & 1167 & 689 & 790 & 867 & 931 \\
\hline Class 2-3.5 kW & \multicolumn{4}{|c|}{ height (m) } & \multicolumn{4}{|c|}{ height (m) } \\
\hline Turbine & 10 & 15 & 20 & 25 & 10 & 15 & 20 & 25 \\
\hline Inclin $3000-3 \mathrm{~kW}$ (HAWT) & 5079 & 5841 & 6419 & 6886 & 5079 & 5486 & 5787 & 6027 \\
\hline Windfox $-3 \mathrm{~kW}$ (HAWT) & 5830 & 6751 & 7444 & 8002 & 5830 & 6324 & 6687 & 6975 \\
\hline WindRotor WRE.030-3 kW (VAWT) & 1617 & 2017 & 2344 & 2623 & 1617 & 1827 & 1988 & 2120 \\
\hline Cleanfield-3.5 kW (VAWT) & 2759 & 3400 & 3916 & 4351 & 2759 & 3096 & 3353 & 3563 \\
\hline Class 5-6 kW & \multicolumn{4}{|c|}{ height (m) } & \multicolumn{4}{|c|}{ height (m) } \\
\hline Turbine & 10 & 15 & 20 & 25 & 10 & 15 & 20 & 25 \\
\hline EasyWind 6 AC—6 kW (HAWT) & 8815 & 10438 & 11657 & 12634 & 8815 & 9685 & 10324 & 10832 \\
\hline Maxy Vertical Wre $0.62-6 \mathrm{~kW}$ (VAWT) & 3420 & 4281 & 4991 & 5601 & 3420 & 3870 & 4218 & 4504 \\
\hline Class $10-12.5 \mathrm{~kW}$ & \multicolumn{4}{|c|}{ height (m) } & \multicolumn{4}{|c|}{ height (m) } \\
\hline Turbine & 15 & 20 & 25 & 30 & 15 & 20 & 25 & 30 \\
\hline BWC Excel-S—10 kW (HAWT) & 5675 & 6716 & 7622 & 8428 & 5080 & 5583 & 6001 & 8428 \\
\hline Windpower Gyro-10 kW (VAWT) & 9917 & 11622 & 13067 & 14324 & 8920 & 9765 & 10457 & 14324 \\
\hline Class 15-17.5 kW & \multicolumn{4}{|c|}{ height (m) } & \multicolumn{4}{|c|}{ height (m) } \\
\hline Turbine & 15 & 20 & 25 & 30 & 15 & 20 & 25 & 30 \\
\hline WT 15000-15 kW (HAWT) & 23819 & 26657 & 28950 & 30872 & 22082 & 23557 & 24734 & 30872 \\
\hline Baywinds 24-15-15 kW (HAWT) & 14199 & 16460 & 18362 & 20008 & 12866 & 13995 & 14916 & 20008 \\
\hline
\end{tabular}


Table 5. Cont.

\begin{tabular}{ccccccccc}
\hline & \multicolumn{3}{c}{ Gela Sub-Urban Area } & \multicolumn{4}{c}{ Gela Rural Area } \\
\hline Class 20-25 kW & \multicolumn{3}{c}{ height $(\mathbf{m})$} & \multicolumn{4}{c}{ height (m) } \\
Turbine & 15 & 20 & 25 & 30 & 15 & 20 & 25 & 30 \\
FL-20 kW (HAWT) & 38120 & 42542 & 46042 & 48932 & 35361 & 37706 & 39556 & 48932 \\
Big Star Vertical-20 kW (VAWT) & 15615 & 18020 & 20081 & 21891 & 14219 & 15400 & 16373 & 21891 \\
\hline
\end{tabular}

To obtain an additional comparative assessment of the different performance of turbines, the capacity factor will be evaluated. Capacity factor is the energy generated during the year divided by the rated power multiplied by the number of hours in the year.

To calculate the capacity factor has been considered the share of 25 meters for the rural area (Figures 10 and 11) and 15 meters in the case of sub-urban area (Figures 12 and 13).

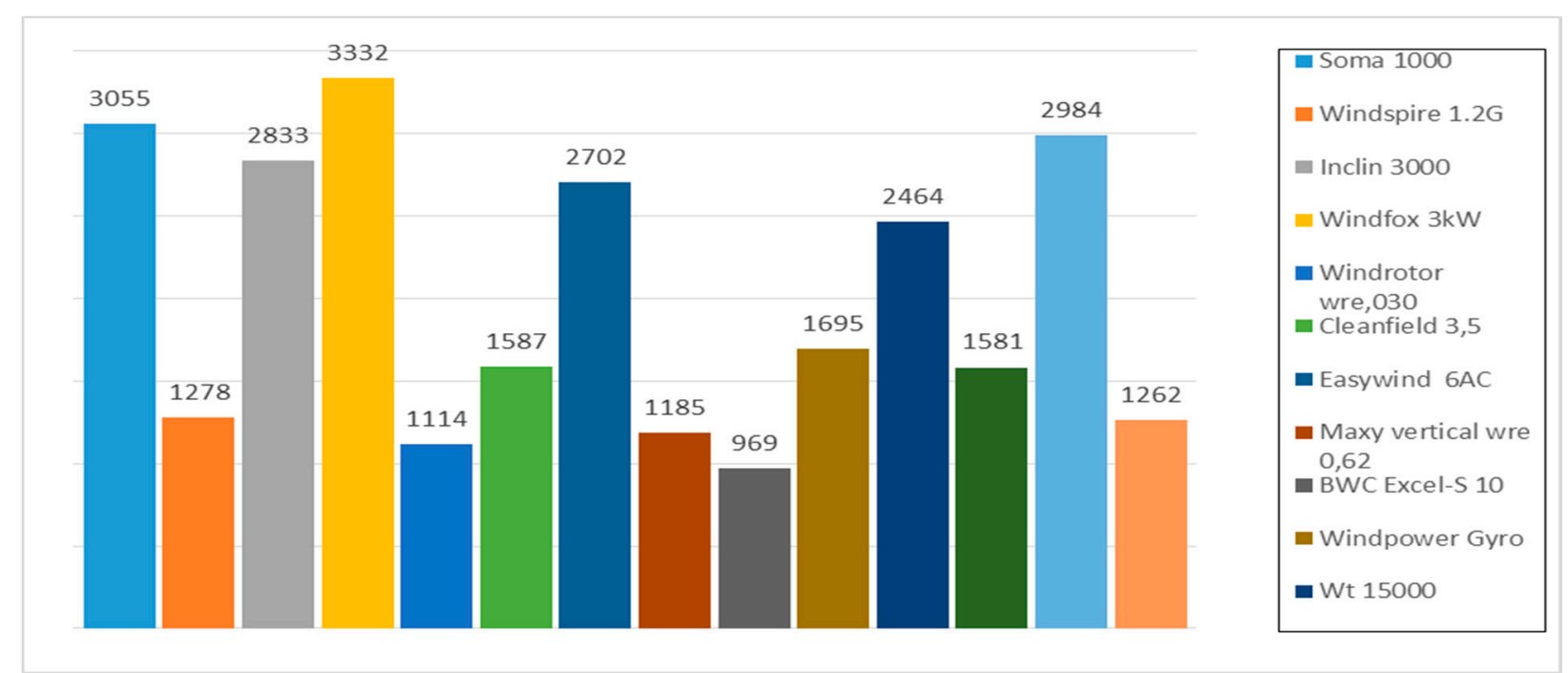

Figure 10. Capacity factor $\mathrm{h}=25 \mathrm{~m}$ (Enna rural area).

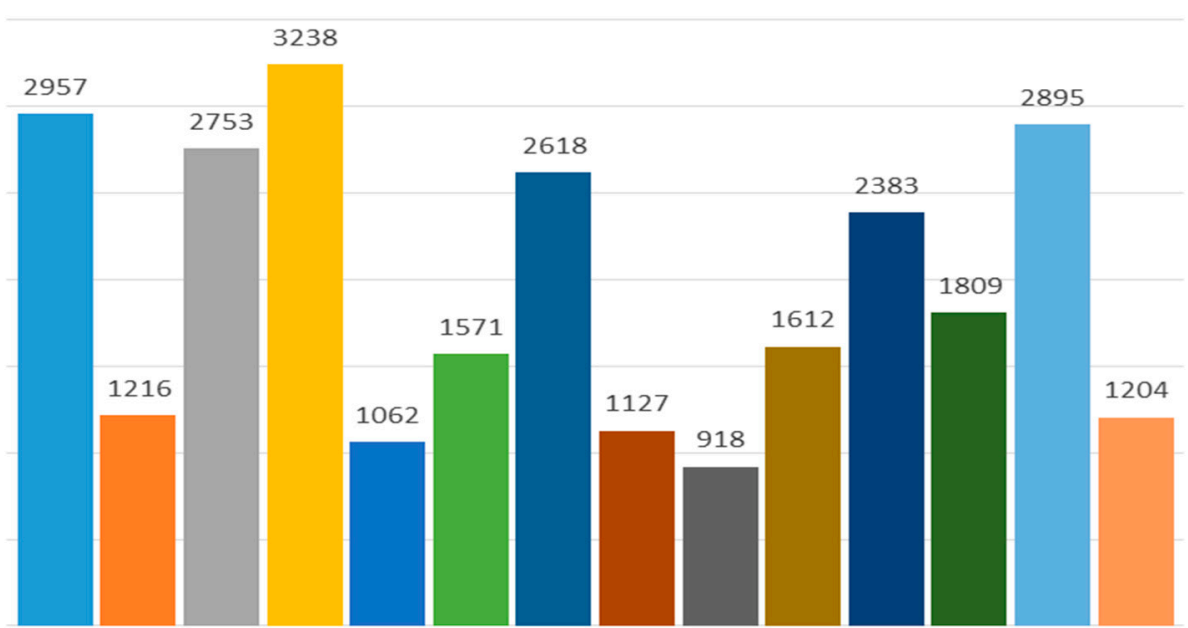

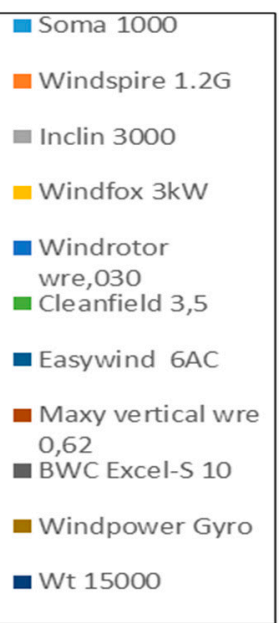

Figure 11. Capacity factor $h=25 \mathrm{~m}$ (Enna suburban area). 


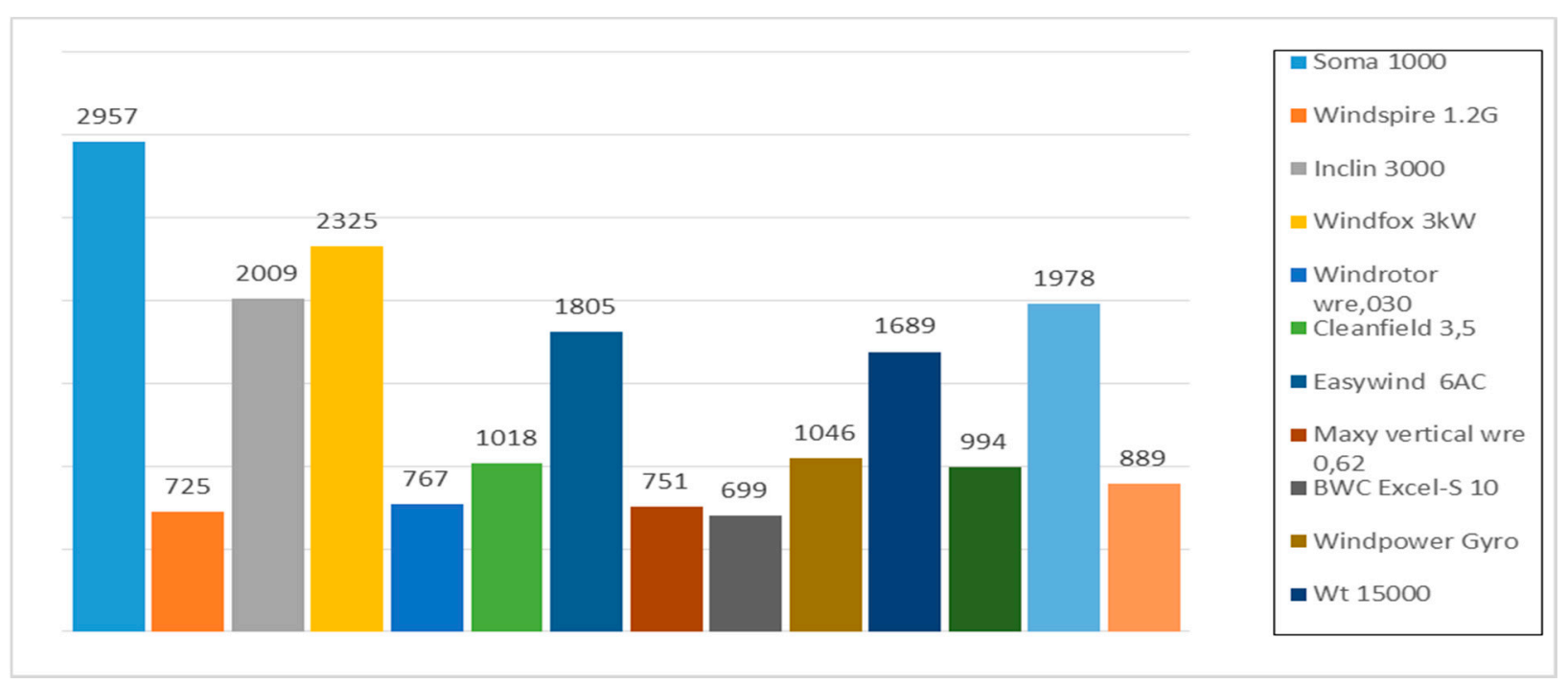

Figure 12. Capacity factor $\mathrm{h}=25 \mathrm{~m}$ (Gela rural area).

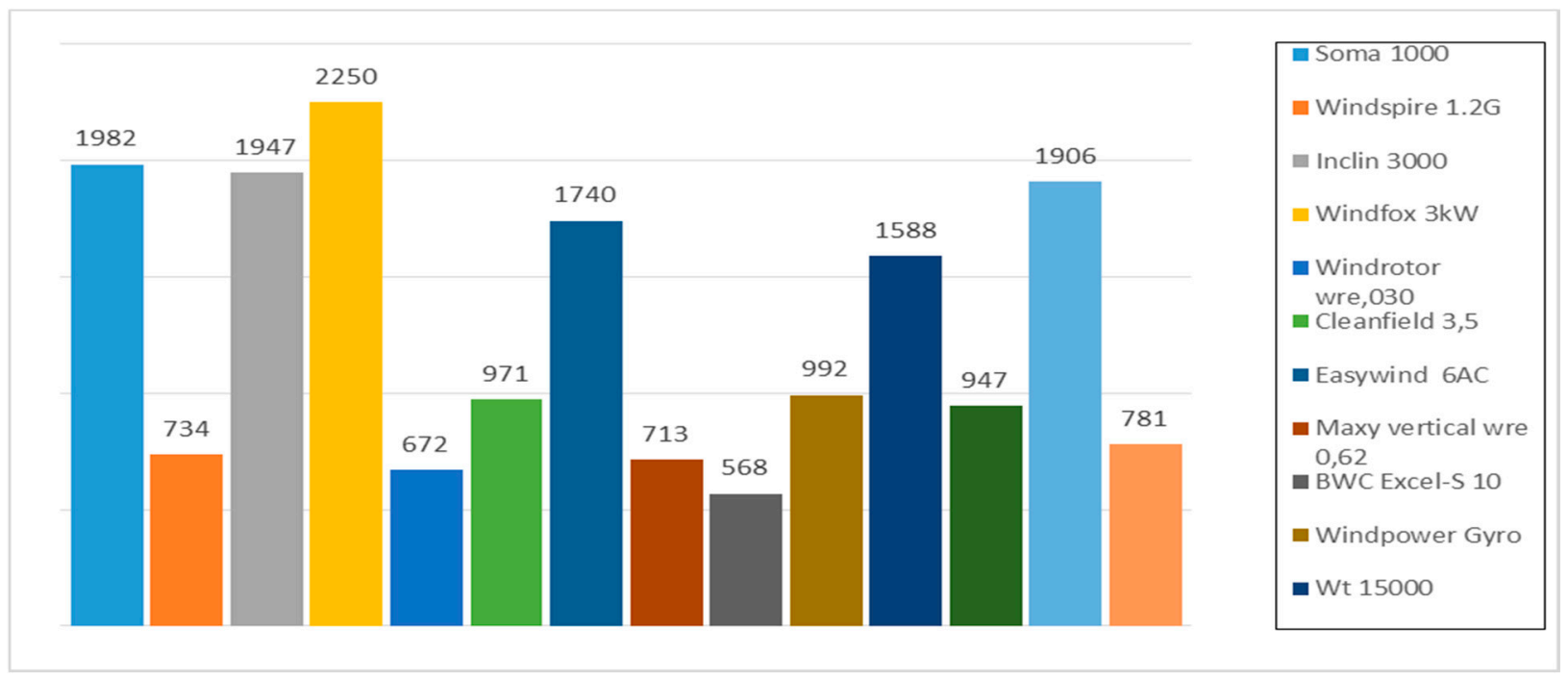

Figure 13. Capacity factor $h=25 \mathrm{~m}$ (Gela suburban area).

The graphs show that for both stations and for each type of terrain the horizontal axis wind turbines produced more energy than the vertical axis. Only in the class from 10 to $12.5 \mathrm{~kW}$ the VAWT produces about $10 \%$ in more than HAWT (this percentage is reduced at the Gela site).

This difference depends from power curves (Figure 14) of two turbines; in fact Windpower Gyro is characterized by a cut-in wind speed of $3.2 \mathrm{~m} / \mathrm{s}$ and by a cut-off wind speed of $24 \mathrm{~m} / \mathrm{s}$ while the BWC Excel-S has a higher starting speed $(3.6 \mathrm{~m} / \mathrm{s})$ and a smaller stop speed $(16.1 \mathrm{~m} / \mathrm{s})$.

Comparing all classes it follows that the turbine with the major capacity factor is the Windfox $3 \mathrm{~kW}$; the one that presents a lower capacity is the BWC Excel-S (either with horizontal axis). 
class $10-12.5 \mathrm{~kW}$

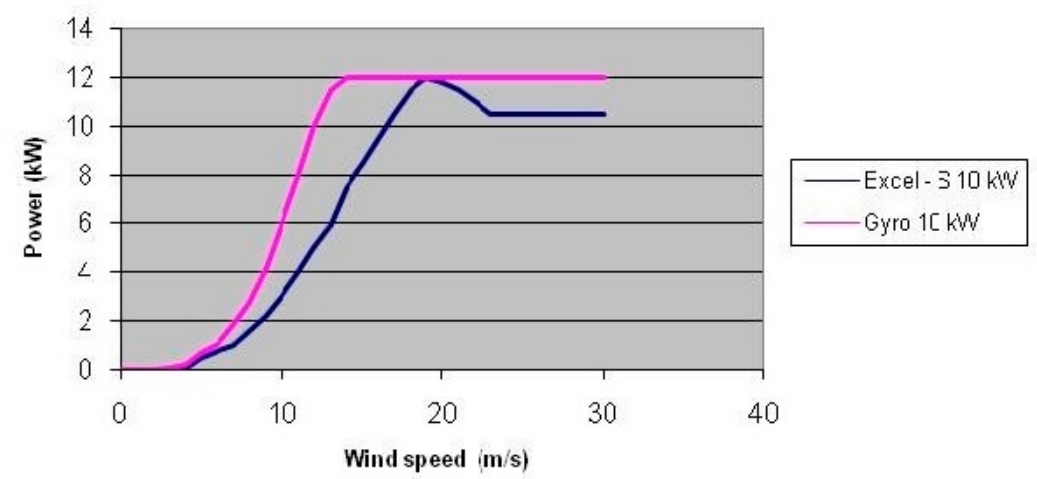

Figure 14. Power Curves.

\subsection{Economic Analysis}

The following economic analysis has used values derived from market research on the cost of small turbines previously analyzed, obtained by the companies that work in the sector.

In the first phase the final expenditure commitments for each turbine was computed, given by the sum of the costs of various components (generator, inverter, control panel, etc.). However, frequently producers do not provide the cost of the accessories and, therefore, it is impossible to do a real evaluation of costs and, in particular, their comparison [16]. Therefore, in order to make a comparable cost of the turbines, the authors have considered the specific costs for every $\mathrm{kW}$ installed.

In order to obtain the payback return the annual revenues obtainable for every value of productivity have been calculated, such as the amount of the tariff that is accessed. In this study an all-inclusive rate was applied that provides an incentive payment of $€ 0.30$ per $\mathrm{kWh}$ transferred to the electricity grid.

The relationship between the specific cost and revenues allowed to obtain the payback period are found in Figures 15 and 16. Figures 15 and 16, respectively, show the payback period for Windfox $3 \mathrm{~kW}$ turbines (major capacity factor) and for the BWC Excel-S (lower capacity factor).

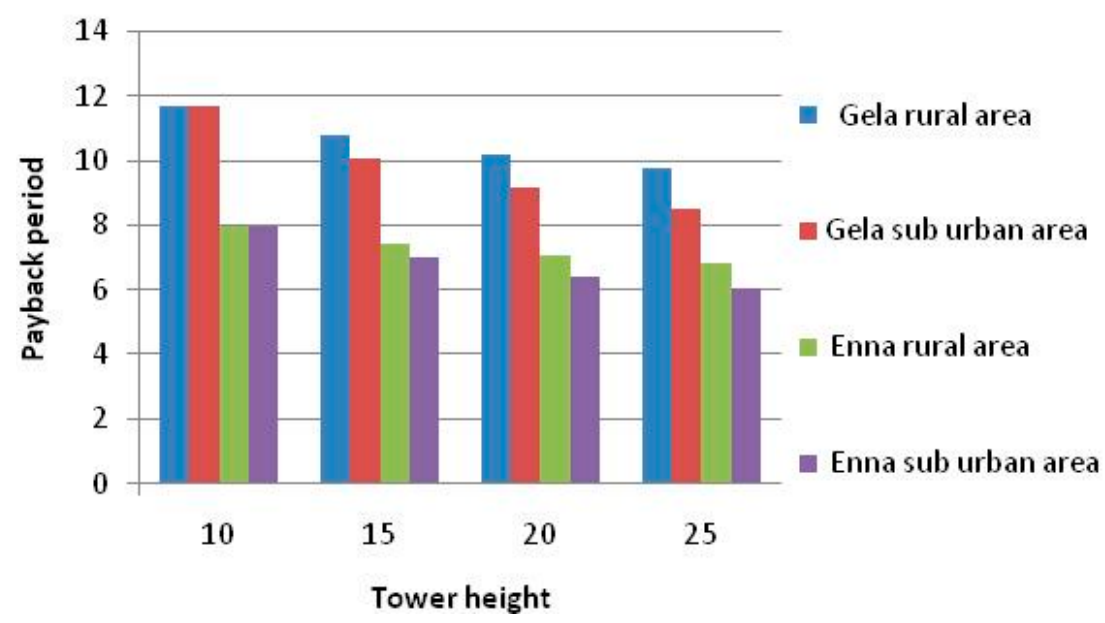

Figure 15. Payback Period Windfox $3 \mathrm{~kW}$. 


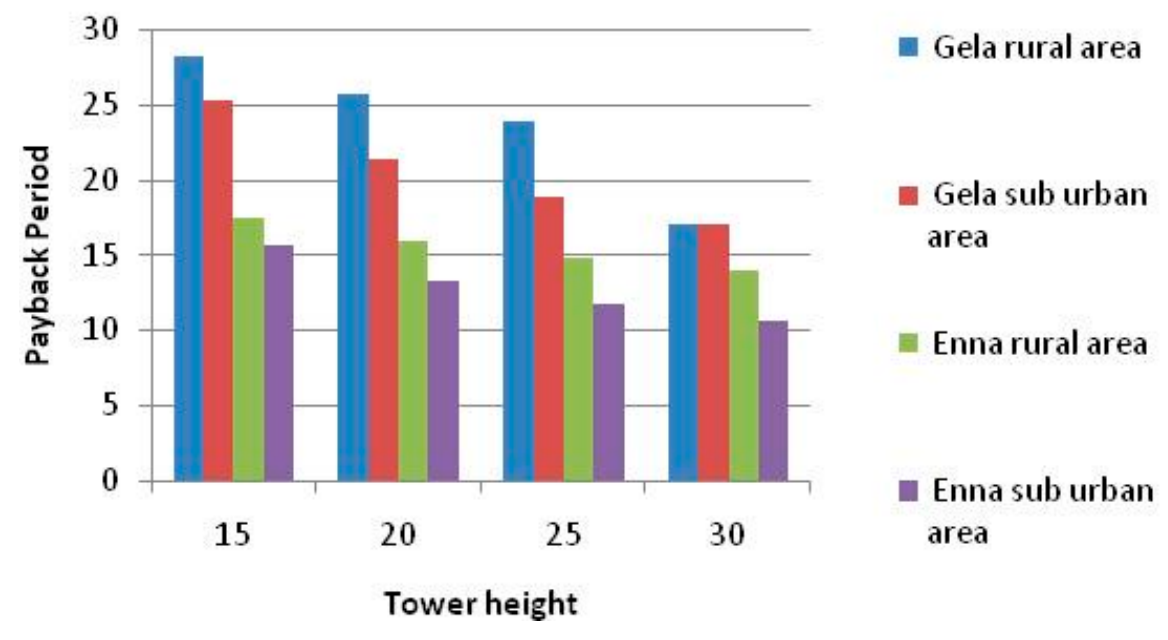

Figure 16. Payback Period BWC Excel-S.

Figure 16 (BWC Excel-S) shows an increase in payback period resulting (except for the station of Enna for both terrains) in higher than the maximum period of incentive. In this case after expiry of 15 years, you can continue to sell energy to the grid with the procedures and the prices guaranteed by the simplified purchase and resale arrangements with small producers. Under these arrangements, producers - with plants of a capacity not exceeding 10 MVA or non-schedulable renewable electricity generation plants of any capacity - may sell the electricity injected into the grid to ESM (Energy Services Manager is the publicly-owned company which promotes and supports renewable energy sources in Italy), as an alternative to bilateral (or over-the-counter) contracts or direct trading in the power exchange. The electricity price that ESM pays to these producers is set every hour in the power exchange, in the market zones where their plants are located.

\section{Conclusions}

Modern large turbines, used mainly in wind farms to produce electricity, represent a mature technology. Small wind turbines have, to date, not received the same attention as their large counterparts.

This work fits in this framework by developing an energy and economic analysis developed through the exercise of certain micro turbines available on the market.

This study showed that the choice of turbine is closely related to the wind conditions and to the type of terrain.

Due to the high cost of small systems, their diffusion is closely related to financing and government incentives. As with European countries, Italy has recently introduced economic incentives lead to increased consumption of wind power.

The Ministerial Decree of 18 December 2008 have introduced measures, in particular, the wind farm whit a annual average production ranging from 1 to $200 \mathrm{~kW}$ can sell the electricity at a price of $0.30 € / \mathrm{kWh}$ for a maximum period of 15 years.

The opportunity offered by the Italian legislative framework allows more attention to be drawn to a new potential market: the urban areas. 


\section{Author Contributions}

All authors contributed to writing the article on equal terms. All authors read and approved the final manuscript.

\section{Conflicts of Interest}

The authors declare no conflict of interest.

\section{Nomenclature}

HAWT is the Horizontal Axis Wind Turbine;

VAWT is the Vertical Axis Wind turbine;

DIA is the simple declaration of the opening activity;

$\mathrm{GC}$ is the green certificate;

$\alpha$ is the wind shear exponent;

$c$ is the scale factor $(\mathrm{m} / \mathrm{s})$;

$\mathrm{h}_{0}$ is the surface roughness;

$n$ is the wind speed bins;

$k$ is the shape factor (dimensionless);

$H\left(U_{i}\right)$ is the number of hours in wind speed bin $U_{i}$;

$P\left(U_{i}\right)$ is the power output at that wind speed;

$s$ is the calm wind frequency (in percentage);

$t(v)$ is the Weibull Distribution;

$v$ is the wind speed $(\mathrm{m} / \mathrm{s})$.

\section{References}

1. Vogiatzis, N.; Kotti, K.; Spanomitsion, S.; Stoukides, M. Analysis of wind potential and characteristics in north Aegen, Greece. Renew. Energy 2009, 29, 1193-1208.

2. Hopkins, W. Small to medium size wind turbines: Local use of a local resource. Renew. Energy 1999, 16, 944-947.

3. Kasbadji, N. Wind energy potential of Algeria. Renew. Energy 2000, 21, 553-562.

4. Bilgili, M.; Sahin, B.; Kahraman, A. Wind energy potential in Antakya and Iskenderun regions, Turkey. Renew. Energy 2004, 29, 1733-1745.

5. Mathew, S.; Pandey, K.P.; Anil Kumar, V. Analysis of wind regimes for energy estimation. Renew. Energy 2002, 25, 381-399.

6. Lange, B.; Larsen, S.; Hojstrup, J.; Barthelmie, R. Importance of thermal effects and sea surface roughness for offshore wind resource assessment. J. Wind Eng. Ind. Aerodyn. 2004, 92, 959-988.

7. Rehman, S.; Al-Abbadi, N.M. Wind shear coefficients and energy yield for Dhahran, Saudi Arabia. Renew. Energy 2007, 32, 738-749.

8. Cabello, M.; Orza, J.A.G. Wind speed analysis in the province of Alicante, Spain. Potential for small-scale wind turbined. Renew. Sustain. Energy Rev. 2010, 14, 3185-3191. 
9. Culotta, S.; Messineo, A.; Messineo, S. The Application of Different Model of Multi-Layer Perceptrons in the Estimation of Wind Speed. Adv. Mater. Res. 2012, 452-453, 690-694.

10. Messineo, A.; Culotta, S. Evaluating the Performances of Small Wind Turbines: A Case Study in the South of Italy. In Proceedings of the Energy Proceia 16 (PART A), Pages International Conference on Future Energy, Environment, and Materials, FEEM 2012, Hong Kong, China, 12-13 April 2012; pp. 137-145.

11. Franzitta, V.; di Dio, V.; Milone, D.; Pitruzzella, S.; Trapanese, M.; Viola, A. Design of Bilateral Switched Reluctance Linear Generator to Convert Wave Energy: Case Study in Sicily. Adv. Mater. Res. 2014, doi:10.4028/www.scientific.net/AMR.860-863.1694.

12. Bizzarri, G.; Lambertini, E.; Matteucci, F.; Rialti, M. Sistemi Microeolici nel Mercato Energetico Italiano: Previsione di Diffusione Tecnologica Attraverso uno Studio Delle Loro Potenzialità $65^{\circ}$. In Proceedings of the Congresso Nazionale ATI, Chia Laguna Resort, Cagliari, Italy, 13-17 September 2010.

13. Burton, T.; Sharpe, D.; Jenkins, N.; Bossanyi, E. Wind Energy Handbook; John Wiley \& Sons, Ltd.: Hoboken, NJ, USA, 2001.

14. Ahmeda, S.A.; Mahammeda, H.O. A Statistical Analysis of Wind Power Density Based on the Weibull and Ralyeigh models of Penjwen Region Sulaimani/Iraq. Jordan J. Mech. Ind. Eng. 2012, 6, 135-140.

15. Ulgen, K.; Hepbasli, A. determination of Weibull parameters for wind energy analysis of İzmir, Turkey Ege University, Ismir, İzmir, Turkey. Int. J. Energy Res. 2002, 26, 495-506.

16. Asdrubali, F.; Baldinelli, G.; D’Alessandro, F.; Scrucca, F. Life Cycle Assessment of electricity production from renewable energies: Review and results harmonization. Renew. Sustain. Energy Rev. 2015, 42, 1113-1122.

(C) 2015 by the authors; licensee MDPI, Basel, Switzerland. This article is an open access article distributed under the terms and conditions of the Creative Commons Attribution license (http://creativecommons.org/licenses/by/4.0/). 